\title{
Meninxes, líquido cefalorraquídeo e barreira hematoencefálica
}

\author{
Carmen Díaz Ruiz \\ Ana M. Muñoz Patiño \\ Jannette Rodríguez Pallares \\ Área de Anatomía e Embrioloxía Humana \\ Departamento de Ciencias Morfolóxicas \\ Facultade de Medicina
}

\section{unidadesdiddácticas}


(C) Universidade de Santiago de Compostela, 2015

\section{Deseño e maquetación \\ J. M. Gairí}

\section{Edita}

Servizo de Publicacións e Intercambio Científico da Universidade de Santiago de Compostela usc.es/publicacions

ISBN

978-84-16533-23-7

$\mathrm{DOI}$

http://dx.doi.org/10.15304/9788416533237 
MATERIA: Neuroanatomía

TITULACIÓN: Grao en Medicina

PROGRAMA XERAL DO CURSO

Localización da presente unidade didáctica

BLOQUE I. ASPECTOS BÁSICOS DA ESTRUTURA E FUNCIÓN DO SISTEMA NERVIOSO

BLOQUE II. MORFOLOXÍA EXTERNA DO SISTEMA NERVIOSO CENTRAL

Unidade I. Morfoloxía externa do encéfalo e da medula espiñal

Unidade II. Meninxes, líquido cefalorraquídeo e barreira hematoencefálica

Unidade III. Vascularizacion do sistema nervioso central

Vascularizacion arterial do encéfalo

Vascularizacion venosa do encéfalo

Vascularizacion arterial da medula espiñal

Vascularizacion venosa da medula espiñal

BLOQUE III. ESTRUTURA DO SISTEMA NERVIOSO CENTRAL

BLOQUE IV. ANATOMÍA DOS PARES CRANIAIS

BLOQUE V. ANATOMÍA DOS ÓRGANOS DOS SENTIDOS 
ÍNDICE

\section{CONTEXTUALIZACIÓN}

Presentación

Xustificación. Relevancia da unidade e relación con outros temas

Duración

OBXECTIVOS

METODOLOXÍA DIDÁCTICA, RECURSOS NECESARIOS E ACTIVIDADES

ACTIVIDADES PROPOSTAS

OS CONTIDOS BÁSICOS

AVALIACIÓN DA UNIDADE DIDÁCTICA

BIBLIOGRAFÍA 


\section{CONTEXTUALIZACIÓN}

\section{Presentación}

Esta unidade didáctica está dedicada ao estudo dos "Sistemas de protección do sistema nervioso central (meninxes, líquido cefalorraquídeo e barreira hematoencefálica)".

Inclúese dentro da materia obrigatoria de Neuroanatomía, unha materia da rama das Ciencias da Saúde enmarcada no Módulo "Morfoloxía, estrutura e función do corpo humano", que se imparte no primeiro semestre do segundo curso do Grao en Medicina da Universidade de Santiago de Compostela. A materia está dedicada ao estudo da morfoloxía externa e a estrutura do sistema nervioso central (SNC) e periférico (SNP) humano.

A Neuroanatomía atópase interrelacionada con varias materias, especialmente con: Citoloxía e Xenética, Histoloxía humana xeral e especial, Anatomía humana xeral e Anatomía do Aparato Locomotor, Fisioloxía xeral e Embrioloxía Humana do mesmo módulo o bloque formativo (do primeiro curso). Ó longo do todo o temario faranse constantes referencias a conceptos introducidos por tales materias.

O estudo de Fisioloxía Médica durante o mesmo cuadrimestre que se imparte neuroanatomía ofrecerá conceptos complementarios útiles para esta materia.

Os coñecementos adquiridos nesta materia serán necesarios para unha correcta asimilación dos conceptos, que se ofertan en Anatomía para técnicas de imaxe no segundo cuadrimestre do segundo curso. Ó mesmo tempo, a Anatomía por técnicas de imaxe contribuirá á compresión e consolidación do estudado en Neuroanatomía, e a achegala ó campo da medicina clínica.

Unha sólida base no coñecemento da estrutura do sistema nervioso (SN) humano é fundamental para a resolución de calquera desafío neurodiagnóstico por parte do futuro médico. Permitiralle comprender e situar correctamente as súas funcións e recoñecer as súas manifestacións tanto en individuos sans coma en individuos enfermos, podendo facer as correspondentes aplicacións á clínica.

Ademais, os contidos que ofrece a Neuroanatomía, son fundamentais para o deseño de modelos de estudo adecuados para a investigación de enfermidades que afectan ó SN e á correcta interpretación de resultados experimentais. Será polo tanto esencial para a formación daqueles que se sintan tamén vocacionados para o labor investigador.

\section{Xustificación. Relevancia da unidade e relación con outros temas}

Aínda que a materia se divide en 5 bloques, non debemos esquecer que o SN funciona coma un conxunto. A pesar da estreita relación con algúns dos temas das outras unidades didácticas deste bloque, os contidos están especialmente vinculados entre si e por iso consideramos a posibilidade de achegala dentro dunha unidade didáctica diferente. Cabe destacar a especial relación dos contidos desta unidade didáctica 
coa unidade didáctica I e III: "Morfoloxía externa do encéfalo e a médula espiñal” e "Vascularización do SN", xa que as meninxes, o líquido cefalorraquídeo (LCR) e mais a barreira hematoencefálica (BHE) están en relación coas estruturas macroscópicas do SNC e as meninxes contribúen á formación das paredes dos seos venosos, polos que acaba drenando o sangue venoso do interior do cranio cara á vena xugular interna e de aí a fóra do cranio.

Por outra banda, os contidos da presente unidade didáctica complétanse cos contidos doutras unidades: na unidade correspondente a vascularización, farase mención á vascularización das meninxes e na unidade dedicada a pares craniais á inervación da duramáter.

O contido desta unidade didáctica é importante para que entendan as consecuencias clínicas das patoloxías relacionadas coas meninxes, a formación do LCR e a disfunción da barreira hematoencefálica que estudarán en cursos superiores.

\section{Duración}

A unidade didáctica contén 1 tema. Para o desenvolvemento da unidade os estudantes necesitarán 2 horas presenciais: unha de seminario e unha clase práctica de laboratorio.

\section{OBXECTIVOS}

A presente unidade didáctica foi elaborada co obxectivo de orientar a aprendizaxe dun tema esencial da materia de Neuroanatomía. Ao longo das clases dedicadas a esta unidade didáctica o alumno deberá achegar os seguintes obxectivos:

- Coñecer a estrutura e importancia funcional das tres meninxes que rodean o cerebro e mais a medula espiñal;

- identificar os diferentes tipos de meninxes pola súa disposición no espazo co respecto ao tecido nervioso e pola súa aparencia, tanto en maquetas como en pezas humanas formolizadas procedentes de cadáveres;

- coñecer as funcións, orixes e destino do LCR;

- comprender a estrutura e función da BHE;

- aplicar correctamente a nomenclatura asociada a esta parte do SN;

- aplicar os coñecementos teóricos á exploración física - neurolóxica básica. 
Relación dos obxectivos da unidade didáctica cos obxectivos globais da materia

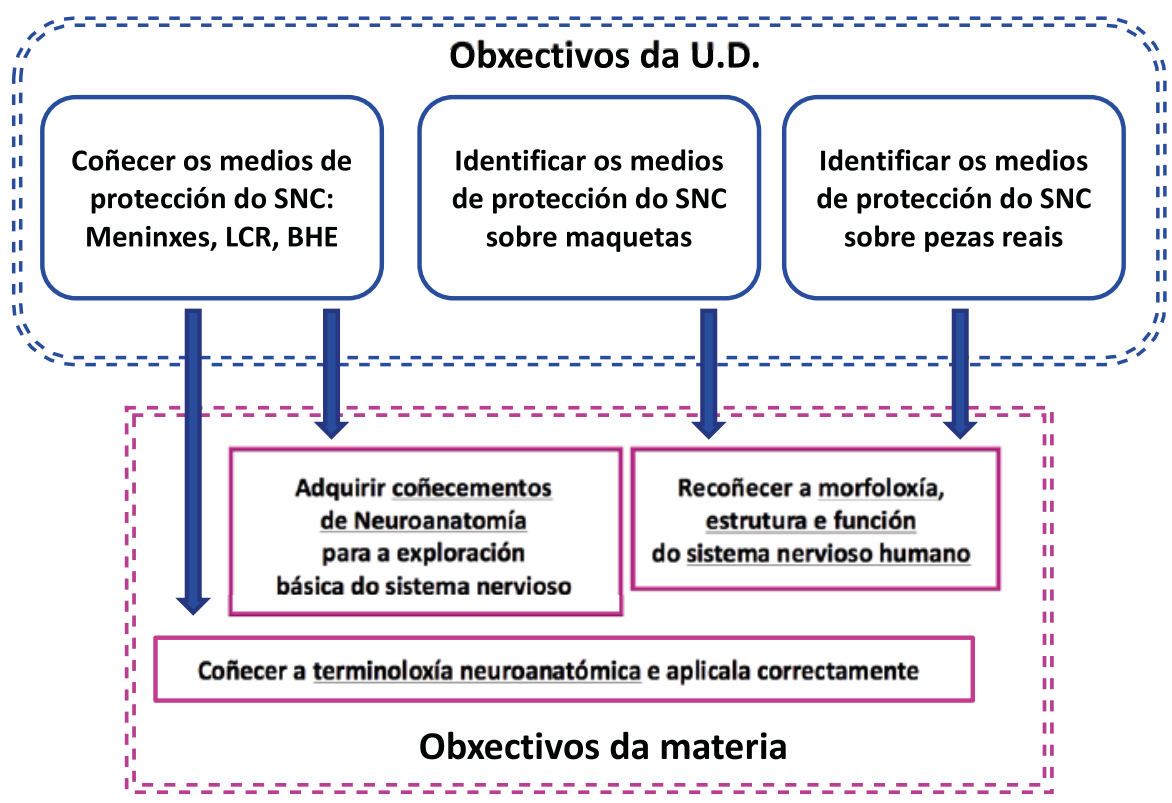

\section{METODOLOXÍA DIDÁCTICA, RECURSOS NECESARIOS E ACTIVIDADES}

Para afondar os contidos de esta unidade de maneira máis activa e participativa, cada grupo dividirase en dous subgrupos e cada un recibirá un seminario e mais unha práctica. Os contidos teóricos presentaranse na clase de seminario. Empregaranse presentacións con diapositivas como guía a exposición con ilustración dos contidos mediante imaxes/esquemas proxectados.

Tamén proporanse preguntas para responder oralmente ou por escrito, ca fin de valorar (e avaliar) se os contidos vanse asimilando axeitadamente.

Deste xeito, abordaranse aspectos clínicos relacionados:

- formularanse preguntas sobre as relacións entre os conceptos de neuroanatomía e a súa aplicación á clínica, posibilitando o razoamento e discusión con máis profundidade e participación dos alumnos ca que poden ter nas clases teóricas.

Para unha integración efectiva e progresiva da materia desta unidade didáctica, como de todos os temas do programa, é moi recomendable que o alumno tome notas e as repase contrastándollas cos manuais recomendados, mais sobre todo cos atlas de neuroanatomía, dada a importancia que ten a visualización no espazo das estruturas do SN para a asimilación dos contidos desta materia. Por mor da dificultade desta materia e máis pola complexidade de todo o relativo ao $\mathrm{SN}$, require levala ao día. 
A clase práctica desenvolverase na sala de técnica anatómica do Departamento de Ciencias Morfolóxicas dispoñible na Facultade de Medicina da USC. A clase práctica pretende ilustrar de forma complementaria e afianzar o explicado na clase teórica e mais no seminario utilizando maquetas anatómicas e material radiolóxico do sistema nervioso central humano, e preparacións de disección obtidas a partir de material post mortem fixado do cerebro e mais a medula conservando íntegras as meninxes.

Coa axuda do atlas e das notas tomadas na clase, os alumnos deberán recoñecer os tres tipos de meninxes estudadas e mais os espazos xerados entre elas, nos distintos materiais presentados, primeiro sobre as maquetas, onde é mais sinxelo recoñecelas e logo sobre as preparacións formolizadas. Ter un caderno persoal de prácticas no que facer debuxos e esquemas que consideren oportunos é moi recomendable pala súa comprensión. Deste xeito, o alumno poderá facerse boa imaxe tridimensional da organización e topografía das meninxes.

Nesta clase os alumnos estarán distribuídos en 6 ou 7 mesas de 7-8 estudantes cada unha. Cando rematen o estudo dos materiais da súa mesa deberán intercambiarse coas outras mesas, para poder acceder a diversidade de materiais dispoñibles.

A clase de prácticas debe entenderse coma clase de estudo, persoal e de maneira aínda máis importante, de estudo en equipo. É recomendable, mais non imprescindible ter estudada a materia para o adecuado aproveitamento desta clase. A sesión práctica é de gran axuda para entender correctamente as notas tomadas na clase expositiva e de seminario, contrastándoas coas imaxes do atlas e das maquetas e pezas formolizadas.

\section{ACTIVIDADES PROPOSTAS}

- Responder ós problemas clínicos propostos nos capítulos 15 e 16 do libro de texto: Neuroanatomía clínica (Snell 2014)

- Preparar e expor un seminario (por alumnos voluntarios, supervisado polo profesor) sobre un dos aspectos clínicos relacionados: por exemplo "Circulación do LCR. Anomalías conxénitas». 


\section{OS CONTIDOS BÁSICOS}

\section{MENINXES, LÍQUIDO CEFALORRAQUÍDEO E BARREIRA HEMATOENCEFÁLICA}

\section{Meninxes}

1.1. Paquimeninxe: Duramáter

1.2. Leptomeinxes:

1.2.1. Aracnoides

1.2.2. Piamáter

1.1. Paquimeninxe: Duramáter: endotelio. Espazo epidural e espazo subdural

* Funcións:

- Protección mecánica

- Protección biolóxica

* Patoloxía:

- meninxites

- meninxiomas

- relación coas diferentes formas de hemorraxias cerebrais

* División:

- espinais ou raquídeas: espazo epidural (inxección epidural)

- craniais

Formacións durais dentro da cavidade cranial: tabiques, seos e confluentes

\subsubsection{Tabiques e seos durais:}

Seos durais: constitúense polas 2 follas ou capas de duramáter que se separan en determinadas zonas, polas que circula sangue venoso procedente das venas cerebrais e mais LCR procedente do espazo subaracnoideo, a través das vilosidades aracnoideas (ver orixe do $L C R$ ):

1.1.1.1. Tenda do cerebelo ou tentorio. 2 circunferencias:

a. Circunferencia maior: No seu percorrido aparecen varios seos:

- Seo petroso superior - aloxa o ganglio do trixémino ou de Gasser:- cavidade trixeminal ou Cavum de Meckel ou cavum do trixémino.

\section{- Seo lateral}

b. Circunferencia menor: Deixa unha abertura para o paso do tronco do encéfalo: o forame oval ou incisura da tenda ou de Pacioni.

c. Na zona lateral onde se unen as 2 circunferencias a ambos os dous lados da sela turca localízase outro seo: seo cavernoso.

O tentorio divide a cavidade cranial en 2 espazos:

1. Compartimento supratentorial

2. Compartimento infratentorial 


\subsubsection{Fouce do cerebro:}

Partes:

2 caras que miran cada unha cara á un hemisferio do cerebro 2 bordos:

1. Bordo superior: percorrido polo seo lonxitudinal superior (ou seo saxital superior)

2. Bordo inferior ou bordo libre: no se ancora á ningunha estrutura en concreto, aloxa o seo lonxitudinal inferior

Base: rexión onde a fouce do cerebro conecta coa tenda do cerebelo: seo recto

Vértice: A fouce ancórase á crista galli

\subsubsection{Fouce do cerebelo:}

Apóiase nas fosas cerebelosas do óso occipital.

Partes:

2 caras que miran cada unha cara á un hemisferio do cerebelo

2 bordos:

1. Bordo posterior: fixado á crista occipital interna

A súa marxe inferior aloxa o seo occipital

2. Bordo anterior libre

\subsubsection{Tenda da hipófise}

Tapiz dural da sela turca, deixa un orificio para o tracto hipofisario.

Seo circular, ou coronario, ou seo intercavernoso (entre os 2 seos cavernosos), en torno ao talo da hipófise. Ten unha comunicación importante coa vena facial a través da vena oftálmica superior. Esta é a vía pola que unha infección pode

\subsubsection{Confluentes:} trasladarse dende á pel da cara ata os seos cavernosos.

1.1.1.1. Prensa de Herófilo ou confluente maior ou confluente magno. Confluente dos seos

\subsubsection{Seo Cavernoso}

\subsection{Leptomeninxes}

1.2.1. Aracnoides: está constituída por células mesoteliais planas.

A aracnoides forma pontes sobre os sucos na superficie do encéfalo.

Entre a aracnoides e a piamáter: espazo subaracnoideo polo que circula LCR (importante para punción lumbar).

Trabéculas subaracnoideas: prolongacións filiformes de tecido conxuntivo que atravesan o espazo subaracnoideo. Están especialmente desenvolvidas na cisterna magna.

As prolongacións filiformes dispostas a ambos os dous lados da medula espiñal reciben o nome de ligamentos dentados.

As estruturas que pasan nun ou outro sentido entre o cerebro e o cranio polos seus orificios, deben pasar a través do espazo subaracnoideo: to- 
das as arterias e venas cerebrais atópanse neste espazo, igual que os nervios craniais.

Ás veces, o espazo subaracnoideo, entre a aracnoides e a piamáter é moito máis voluminoso e forma cisternas. Correspóndense as zonas onde se encurva o sistema nervioso.

Cisternas (Ver Haines, Capítulo 7):

- da lámina terminal ou supraóptica

- quiasmática

- Interpeduncular

- prepontina ou pontina

- confluente central ou anterior

- espiñal

- magna

- cerebelosa superior

- confluente superior

- ambiens

Vilosidade ou granulacións aracnoideas: prolongacións do aracnoides cara á duramáter, que a atravesan ata a folla interna. Só aparecen nas rexións dos seos.

* Funcións:

Onde se produce a absorción do LCR, intercambio cara ao sistema venoso.

As veces as granulacións son moi grandes (medran coa idade), tamén se poden calcificar e poden chegar a deixar marcas no Óso: corpúsculos ou fosas de Pacioni

Algúns autores chaman corpúsculos de Pacioni as vilosidades ou granulacións aracnoideas.

1.2.2. Piamáter: Está constituída por células mesoteliais planas dispostas de forma laxa.

É a meninxe máis interna do sistema nervioso e tamén penetra nos sucos: acompaña parcialmente o inicio dos sucos e dos vasos que se introducen en eles. As arterias cerebrais que penetran no tecido cerebral arrastran unha vaina de piamáter con elas.

Por debaixo dela hai un estrato de células gliais que a separan do sistema nervioso: a membrana limitante glial.

Contribúe a formar os teitos dos ventrículos terceiro e cuarto constituíndo parte da tea coroidea, que se asocia cos vasos formando os plexos coroideos (Ver Snell, Capítulo 16 e Haines, Capítulo 6). 
* Estrutura da tea coroidea:
a) células endoteliais na parede dos capilares ou plexos coroideos
b) membrana basal continua que rodea o capilar
c) piamáter
d) epitelio ependimario

\section{Líquido cefalorraquídeo (LCR)}

É un fluído transparente e acelular. Deriva do plasma sanguíneo (ultrafiltrado). Prodúcense 0.5 litros ao día aproximadamente. Atópase a nivel de ventrículos e no espazo subaracnoideo. Aproximadamente 25 cc en ventrículos e 125 cc no espazo subaracnoideo.

*Orixe:

- nos plexos coroideos. Un 60-70\% procede dos plexos coroideos e vai ós ventrículos.

- da auga derivada do metabolismo.

* Circuíto (Ver Netter, Sección 1):

- Circula dos ventrículos cara ao espazo subaracnoideo, comunicados polo burato de Luschka e o burato de Magendie.

- Reabsórbese nas vilosidades aracnoideas, sobre todo á nivel do seo lonxitudinal superior.

* Funcións:

- Hidráulica - O encéfalo pode pesar 1400 g., o LCR 50g. Pode dicirse que o encéfalo flota en LCR.

- Metabólica - circulan nutrientes e desfeitos relacionados co metabolismo celular

- Diagnóstica - para medir parámetros relacionados con determinadas patoloxías, cóllese LCR cunha punción lumbar.

Exem: hidrocefalia

*Patoloxía:

Aumento anormal do tamaño dos ventrículos, ás veces producido por unha excesiva formación de LCR. Pode xerar un incremento no volume do cranio en cativos nos que aínda non suturaron os ósos do cranio.

Poden ter ollos en sol nacente (media lúa, non poden mirar cara arriba) porque os pares craniais poden estar presionados na zona do seo cavernoso.

Hidrocefalia non comunicante: cando hai obstrución nalgún punto. Hidrocefalia comunicante: cando hai problemas de reabsorción.

Exvacuo: dexeneración ou atrofia de cortiza cerebral -consecuentemente os ventrículos agrándanse

\section{Barreira hematoencefálica (BHE):}

* Función: protección do cerebro e a medula espiñal fronte a fármacos ou outros materiais exóxenos potencialmente tóxicos. Permite a entrada de gases e nutrientes no tecido nervioso. 
* Estrutura (ver Snell, Capítulo 16):

a) células endoteliais na parede dos capilares. As unións estreitas entre elas son as responsables da BHE

b) membrana basal continua que rodea o capilar

c) podocitos ou prolongacións pediculadas dos astrocitos

* Tipos:

1. Barreira física, morfolóxica entre o tecido nervioso e o sangue. As unións estreitas entre as células endoteliais limitan o paso de determinadas sustancias, para que non todo chegue ao tecido nervioso.

Os astrocitos son os indutores da formación da BHE, e segregan factores tróficos para que a BHE funcione correctamente.

Para que unha sustancia entre no sistema nervioso ten que atravesar o citoplasma das células endoteliais (son necesarios transportadores e mais encimas, que favorezan o tránsito).

2. Tamén existe BHE entre o sangue e o LCR. Entre os plexos coroideos e o interior dos ventrículos existe unha membrana basal envolvente na parede dos capilares, piamáter e mais una monocapa de células ependimarias.

3. Barreira aracnoidea: células do aracnoides teñen unións ocluentes.

\section{Órganos circunventriculares o «fiestras do encéfalo" :}

Son estruturas do sistema nervioso onde a BHE é moito menor, non está ben constituída ou non existe.

Deste xeito o sistema nervioso pode responder a certas sustancias. Dispóñense o redor dos ventrículos, sobre todo do terceiro ventrículo.

Órganos circunventriculares impares:

1. Órgano subtrigonal- a nivel de piares anteriores.

Relaciónase coa detección de cambios na concentración hidrosalina.

2. Órgano vasculoso - na lámina terminal.

Relacionado con diferentes tipos de neuropéptidos.

3. Neurohipófise - lóbulo posterior da hipófise.

Produción de hormonas.

\section{Eminencia media o tuber cinereum.}

Relacionada con hormonas hipotalámicas.

5. Órgano subcomisural- por debaixo da comisura branca posterior. Relacionado coa composición de diferentes líquidos corporais.

6. Glándula pineal ou epífise - relacionada coa secreción de melatonina. O único órgano circunventriculares que é par:

Área postrema (unha a cada lado da liña media) no cuarto ventrículo. Funciona como quimiorreceptor 


\section{AVALIACIÓN DA UNIDADE DIDÁCTICA}

A cualificación de cada alumno farase mediante a realización dun exame final de teoría e un exame de prácticas. Aprobar as prácticas será imprescindible para poder ser avaliado.

O exame de teoría cubrirá a materia dos cinco bloques de forma proporcional ao peso do temario e consistirá en preguntas tipo test de opción múltiple. Ao contido desta unidade didáctica corresponderalle aproximadamente un $5 \%$ das preguntas do primeiro bloque, ao que pertence. A nota do exame teórico corresponde ao $80 \%$ da nota final.

O exame de prácticas consistirá en preguntas de identificación das estruturas neuroanatómicas estudadas nas maquetas e mais preparacións formolizadas utilizadas nas clases de prácticas. Ao contido desta unidade didáctica corresponderalle un $5 \%$ das preguntas do exame práctico. A nota do exame teórico corresponde ao $20 \%$ da nota final.

A nota final debe superar o $60 \%$ para aprobar e obterase da suma ponderada da nota do exame teórico e mais do exame práctico.

Se non se aproba a teoría, pero si as prácticas, conservarase a nota deste último, mais só ata a recuperación de Xuño.

\section{BIBLIOGRAFÍA}

Todos os recursos mencionados neste apartado están dispoñibles para o alumnado matriculado na USC na biblioteca da Facultade de Medicina, ou son de acceso libre en internet.

1.- Atlas de Anatomía y Neuroanatomía:

- Sobotta. Atlas de Anatomía Humana. 23a Ed. Elsevier España 2012.

- Schünke, M. Prometheus, texto y atlas de anatomía. Tomo 3. 3a ed. Panamericana, 2015.

- Netter, FH. Atlas de anatomía humana. 5a ed. Mason Elsevier, 2011.

2.- Libros de Texto de Neuroanatomía:

- Snell, RS. Neuroanatomía clínica. 7a ed. Ed: Lippincott Williams \& Wilkins, 2014.

- Fitzgerald, T. Neurantaomia clinica y neurociencia. 6ạ ed. Elsevier Saunders. 2012.

- Haines, DE. Principios de Neurociencia. 4ạ Ed. Elsevier Science. 2013.

3- Recursos en internet: Anatomy of the human body: [citado 1.09.15]

http://www.bartleby.com/107/193.html

http://www.bartleby.com/107/194.html

[citado 1.09.15]

4- Vídeos:

Acland, R.D. Acland's DVD Atlas of Human Anatomy. DVD 5: The head and the neck, Part 2. Title 2: the brain and surroundings. Cranial cavity and meninges. Lippincott Williams \& Wilkins. 2004. 


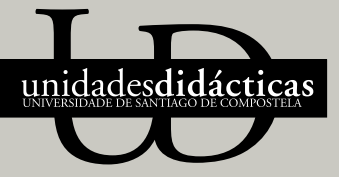

Unha colección orientada a editar materiais docentes de calidade e pensada para apoiar o traballo do profesorado e do alumnado de todas as materias e titulacións da universidade 